\title{
Volcanic sulfur emissions: Estimates of source strength and its contribution to the global sulfate distribution
}

\author{
Hans-F. Graf, Johann Feichter, and Bärbel Langmann
}

Max-Planck-Institut für Meteorologie, Hamburg, Germany

\begin{abstract}
Anthropogenic emission of $\mathrm{SO}_{2}$ and conversion into $\mathrm{SO}_{4}{ }^{2-}$ is argued to be the most important factor damping and modulating the global greenhouse effect. Recent estimates of the relative strength of the three important sources of volatile sulfur $\left(\mathrm{SO}_{2}\right.$ from fossil fuel combustion $\sim 78$ $\mathrm{Tg} \mathrm{S} / \mathrm{yr}$, from biomass burning $\sim 2 \mathrm{Tg} \mathrm{S} / \mathrm{yr}$, and from natural sources $\sim 25 \mathrm{Tg} \mathrm{S} / \mathrm{yr}$ ) suggest an overwhelming effect of the anthropogenic emissions for climate forcing. However, the radiatively relevant product $\mathrm{SO}_{4}{ }^{2-}$ may have different patterns due to the distribution of the sources (some very dense areas near the surface for anthropogenic $\mathrm{SO}_{2}$, formation of $\mathrm{SO}_{2}$ from dimethylsulfide in the marine boundary layer, and emission of volcanic $\mathrm{SO}_{2}$ mostly in the free atmosphere in rural areas). In this paper we study the relative contribution of volcanic $\mathrm{SO}_{2}$ emissions to the atmospheric sulfur budget applying an atmospheric general circulation model including a full sulfur cycle and prescribed source distributions. An off-line analysis tool is applied to determine the radiative forcing of sulfate aerosols. The results show that natural S sources are at least as important as the anthropogenic ones, even though their source strength is much smaller. The reasons are different lifetimes due to different production and emission processes. Therefore, we should improve our knowledge about the volcanic volatile sources and their time-space variability.
\end{abstract}

\section{Introduction}

The role of aerosols in climate change has been emphasized recently in publications of estimates of the direct [Kiehl and Briegleb, 1993] and indirect [Boucher and Lohmann, 1995] radiative forcing of sulfate and sensitivity studies with climate models [Taylor and Penner, 1994; Roeckner et al., 1995; Mitchell et al., 1995]. So far the impacts of anthropogenic sulfate aerosols [e.g., Langner et al., 1992] are seen as the major component of climate affecting sources of volatile sulfur (Table 1). The data given in Table 1 are subject to a high degree of uncertainty, although the general consensus is that about $3 / 4$ of the total sulfur output comes from anthropogenic sources. The main natural sources, dimethylsulfide (DMS) emitted from the oceans and sulfur dioxide $\left(\mathrm{SO}_{2}\right)$ released from volcanoes are of the same magnitude, but, while the oceanic emission level is at mean sea level, the volcanic source in most cases is in the upper part or far above the planetary boundary layer. Most of the volcanic emissions take place in the northern hemisphere (NH) since most active volcanoes are concentrated there (only $18 \%$ are at the southem hemisphere (SH)). The terrestrial emissions and biomass burning seem to be of minor importance compared with the other sulfur sources. However, biomass burning is an important source of other aerosol species like soot, ash, and organics.

The anthropogenic emissions, mainly from fossil fuel combustion, have maxima in the eastern United States, Europe, and, increasingly, China [Langner et al., 1992]. The oceanic sources

Copyright 1997 by the American Geophysical Union.

Paper number 96JD03265.

0148-0227/97/96JD-03265\$09.00 are more concentrated in biologically productive areas of the oceans (e.g. in the upwelling areas and in high latitudes). In contrast, the volcanic sources are organized around the globe at the edges of crustal plates (Figures $1 \mathrm{a}$ and $1 \mathrm{~b}$ ). Since the atmospheric residence time of sulfur species is of the order of 1-2 weeks, the anthropogenic, volcanic, and oceanic sulfate aerosols are well separated geographically.

Even though the natural sources contribute only $1 / 4$ to the total atmospheric sulfur budget, most of them are in remote areas, where the aerosol load is low, and therefore the formation of new particles is more likely than in polluted regions. Additionally, the proximity of the natural sulfur sources to the oceans increases the impact on the radiative fluxes, since maritime clouds are more strongly affected by sulfate aerosols than continental clouds [Platnick and Twomey, 1994]. Maritime clouds which form in aerosol poor air develop large droplets, while the abundance of condensation nuclei over the continents produces more and smaller cloud droplets which reflect incoming solar radiation much more effectively. Therefore the addition of $S$ compounds in marine areas may influence the cloud reflectivity as well as the lifetime of clouds and thus the energy budget at the Earth surface.

In climate research so far the effects only of cataclysmic volcanic eruptions have been studied [e.g., Hansen et al., 1992; Graf et al., 1993] which have the potential to inject aerosol-forming gas directly into the stratosphere producing short-term (few years) climatic effects. Quiescent degassing and moderate eruptions, however, have a long-term effect on the atmospheric composition, and chemical and radiative effects are to date poorly understood. However, these quasi-continuous background emissions may have even stronger climatic impact than the cataclysmic eruptions. The latter ones will not significantly influence the tropospheric sulfur budget. Therefore, for this study we concentrate on smaller eruptions and quiet degassing. 
Table 1. Sulfur Sources From Bates et al. [1992]

\begin{tabular}{lccccc}
\hline & Oceanic & Terrestrial & Volcanic & Biomass & Anthropogenic \\
\hline Northem Hemisphere & 6.4 & 0.2 & 6.7 & 1.2 & 70.4 \\
Southem Hemispher & 9.0 & 0.1 & 2.7 & 1.0 & 7.7 \\
Global & 15.4 & 0.4 & 9.4 & 2.2 & 78.1 \\
\hline
\end{tabular}

Sulfur sources are in teragrams per year.

In many volcanically active areas volcanic emissions contribute significantly to the total emission of sulfur species. In Guatemala, for example, about $0.15 \times 10^{6} \mathrm{t} \mathrm{S/yr}$ sulfur dioxide are degassing [Andres et al., 1992] from nonerupting magma bodies, and the dormant basalt volcano Fuego emits as much as $0.3 \times 10^{6} \mathrm{t}$ $\mathrm{S} / \mathrm{yr}$. These values are much higher than the anthropogenic emissions in this Central American country.

In some cases the volcanic emissions may exceed the anthropogenic even in highly industrialized areas. The European Cooperative Program for Monitoring and Evaluation of the Long-Range Transmission of Air Pollutants (EMEP) data on sulfur emission, for example, give for Sicily a value of $0.1 \times 10^{6} \mathrm{t} \mathrm{S} / \mathrm{yr}$ of sulfur dioxide. Measurements at the volcano Etna [Allard et al., 1991], however, show quasi-permanent emissions of $0.73 \times 10^{6} \mathrm{t} \mathrm{S/yr}$ as an average of the years $1975-1987$. In 1980 a long-lasting active period emitted $1.0 \times 10^{6} \mathrm{t} S$ to the middle troposphere and $0.16 \mathrm{x}$ $10^{6} \mathrm{t} \mathrm{S}$ to the planetary boundary layer [Spiro et al., 1992]. The steady degassing of volcano Ema is estimated as $0.12 \times 10^{6} \mathrm{t} \mathrm{S} / \mathrm{yr}$ by quiet degassing due to, for example, fumaroles. This means that the volcanic emissions of sulfur in this area are at least a factor of 10 higher than the anthropogenic emissions (EMEP) [Saltbones and Dovland, 1986].

In Section 2 we discuss the time-space distribution of volcanic volatile sulfur sources as estimated in several papers on this topic. The best estimate will then be used in a climate sensitivity study in order to investigate the regional and global scale potential effects of the volcanic source on the aerosol content of the atmosphere and on climate. The model is decribed in Section 3 and the resulting sulfate budget is discussed in Section 4. In Section 5 we present estimates of the direct and indirect sulfate forcing and discuss the potential impact of volcanic emissions on climate.

\section{Volcanic Sulfur Emission}

Magmatic gases are in solution in molten rock under high pressure in the Earth's depth. Water, carbon dioxide, and sulfur species are the predominant components. Their relative abundance is

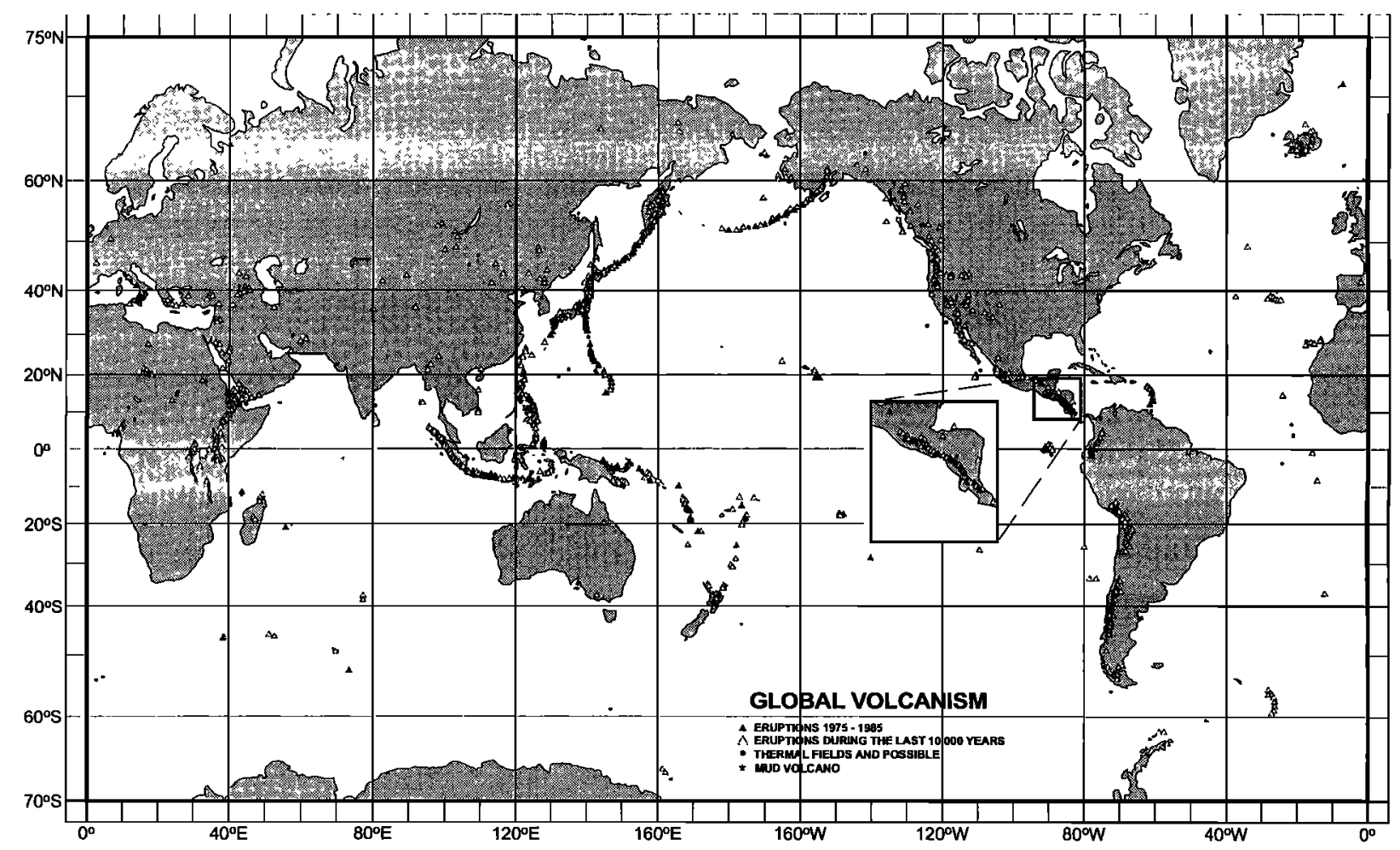

Figure 1a. Active volcanos from $1975-1985$ (solid triangles) and sites with volcanic activity during the last 10,000 years (open triangles). Modified after McClelland et al. [1989], Smithsonian Institution Scientific Event Alert Network (SEAN), Global Volcanism 1975-1985, 1989, back cover, adapted by permission of Prentice Hall, Upper Saddle River, New Jersey. 


\section{Vulkanische Emissionen}

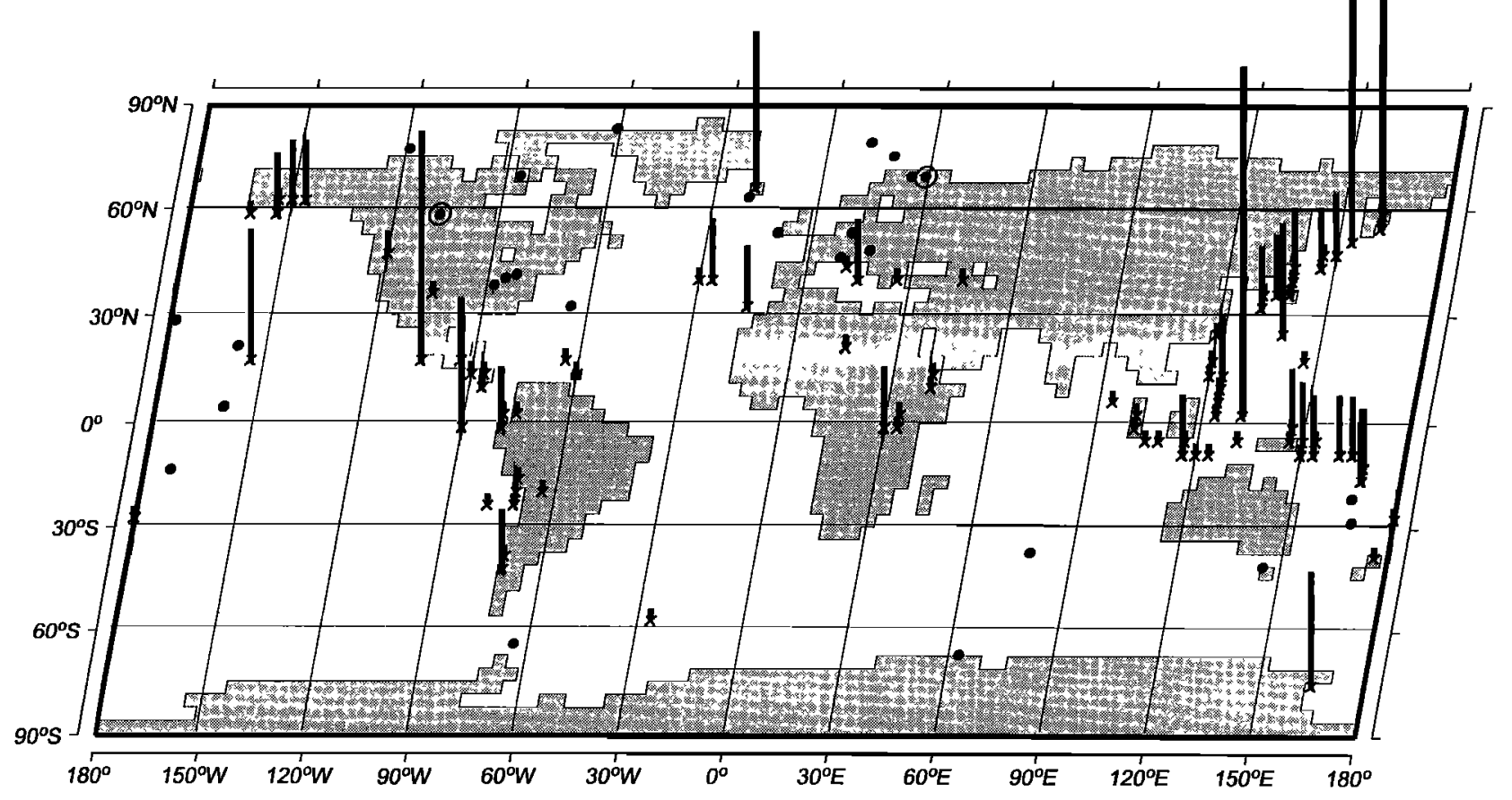

Figure 1b. Volcanic emissions (relative units, global mean $14.0 \mathrm{Tg} \mathrm{S} / \mathrm{yr}$ ) as used in the model calculations. The length of the bars denotes the source strength. Dots denote places with $\mathrm{SO}_{2} / \mathrm{SO}_{4}{ }^{2-}$ observations.

determined by thermodynamic conditions (pressure, temperature, and oxygen volatility). The different magma types are characterized by their chemical compositions. In general, the volatile content of basaltic magmas is lower than that in higher-differentiated magmas. In basalt magmas (especially in alkaline basaltic magmas) the sulfur content is much higher than in higher-differentiated ones, while the higher viscosity of the latter leads to more explosive energy released during eruptions. During the cooling of the rising magma, several components (e.g., $\mathrm{H}_{2} \mathrm{O}, \mathrm{F}$, and $\mathrm{Cl}$ ) are enriched in the magma, while less soluble species like $\mathrm{CO}_{2}$ and $\mathrm{SO}_{2}$ can be exhaled in volatile forms from low-viscosity basaltic magmas [Greenland, 1984]. This noneruptive degassing can also be very efficient. During volcanic eruptions in most cases a higher fraction of $\mathrm{SO}_{2}$ is emitted than that corresponding to the $\mathrm{SO}_{2}$ content of the erupted magma. This discrepancy may be explained by degassing of the magma remaining inside the volcano. Stoiber and Jepsen [1973] estimated $80 \%$ of the ejected sulfur components during eruptions of the volcano Pacaya (Guatemala) stemmed from nonerupted magma. Allard et al. [1994] has estimated this proportion to be as high as $99 \%$ for Stromboli (Italy).

A special type of basaltic magmas, the alkalinic basalt magmas, as found at Mount Etna, Mount Erebus, and Nyiragongo, may have a much higher degassing rate than other basaltic magmas. Indeed, Mount Etna at the east coast of Sicily is the strongest single quasi-permanently degassing volcanic source of $\mathrm{SO}_{2}$ (and $\mathrm{CO}_{2}$ ) known so far [Gerlach, 1991a]. Etna, being an intraplate continental volcano, produces alkaline basaltic magma which is enriched in $\mathrm{CO}_{2}$ by underlying carbonates [Allard et al., 1987]. The neighboring volcanos at the Aeolian Islands, Vulcano and Stromboli, are convergent plate island arc volcanos with tra- chyandesitic magma. Thus even volcanic sources in a short distance may have different characteristics.

A typical phenomenon connected with any kind of volcanic activity is the high temporal variability of the release rate. Besides water vapor and $\mathrm{CO}_{2}, \mathrm{SO}_{2}$ is the most important volatile being emitted. $\mathrm{SO}_{2}$ is the only volcanic gas that frequently is observed with remote sensing techniques (correlation spectrometer, Lidar). In the troposphere, $\mathrm{SO}_{2}$ is quite short-lived as it is efficiently deposited at the ground or transformed into sulfate. In particular, $\mathrm{SO}_{2}$ dissolved in cloud droplets is quickly oxidized. Therefore the regional (scale about $2000 \mathrm{~km}$ ) $\mathrm{SO}_{2}$ distribution is strongly determined by the sources. Unfortunately, these regional figures show a substantial variability. Even at a certain spot, at a volcanic site which is known to be active, the source strength of $\mathrm{SO}_{2}$ can vary over some orders of magnitudes depending on the phase of activity. Hence Rose et al. [1988] reported a $\mathrm{SO}_{2}$ flux of 24,000 metric tons/d during the enuptive phase of St. Augustine volcano in 1986, while a few months later the emission dropped to 380 metric tons/ d. In addition, even at a specific volcano the ratio between output magma and $\mathrm{SO}_{2}$ release can vary by a wide range, making an estimate of the volcanic $\mathrm{SO}_{2}$ source in space and time an extremely difficult task.

Unfortunately, only sporadic measurements of degassing volcanos exist and few time series are available. Additionally, only a small fraction of degassing volcanos has ever been measured. Therefore, without extensive observations, any baseline information on volcanic volatile sources will remain uncertain. The best way to determine the possible impact on atmospheric chemistry and aerosol formation will be to use plausible estimates and per- 
form model sensitivity studies. Even if we knew the source strength of volatile $\mathrm{SO}_{2}$, the fate of this trace gas in the atmosphere is not known a priori. Depending on the height of emission and on the weather conditions, $\mathrm{SO}_{2}$ can reside longer or shorter in the atmosphere. In the presence of hydrometeors (rain, fog, etc.), $\mathrm{SO}_{2}$ will rapidly be oxidized to sulfate and can effectively be deposited.

Figure 1a (based on McClelland et al., [1989]) gives an overview over the areas of active volcanism during the years 1975 1985 , indicating also the known volcanically active regions during the last 10,000 years. These regions are the areas of potential volcanic $\mathrm{SO}_{2}$ release. The columns in the grid cells in Figure $1 \mathrm{~b}$ indicate the strength of the volcanic $\mathrm{SO}_{2}$ source that we used in our general circulation model (GCM) calculation (the landmask corresponds with the horizontal resolution of the circulation model).

Figure $1 \mathrm{~b}$ suggests that, besides the circumpacific "ring of fire", there are only few volcanically active regions. Important ones are in the Mediterranean (Italy and Greece), the rift in northeast Africa, Hawaii, Iceland and the Azores, Cape Verde, and the Canary Islands. The relatively coarse resolution of the atmospheric model helps in getting rid of part of the spatial variability of volcanic activity in so far as only the region of activity is considered and not the active spot itself. In addition, the altitudes of noneruptive degassing are known at least to the degree of vertical resolution of common climate models. In the following we give an estimate on the portion of quiscent degassing and explosive emissions to the total emission of volcanoes, which will be considered in our GCM study.

\section{Quiescent degassing}

Stoiber's estimate for quiescent degassing is based on correlation spectrometer (COSPEC) $\mathrm{SO}_{2}$ measurements and their correlation with plume size (Table 2) observed by Stoiber et al. [1983] at places in Central America. A questionnaire was used to estimate globally the plume sizes and then to combine this size with daily mean $\mathrm{SO}_{2}$ emissions.

The visible plume size is determined by the amount of water vapor being emitted, which can be either meteoric or magmatic. From a "plume census" in 1981/1982, Stoiber et al. [1983] found a total of $6.8 \mathrm{Tg}$ of $\mathrm{SO}_{2}$ from quiet degassing. This estimate can be compared to data compiled by Spiro et al. [1992] who, using the same method, estimate $5.4 \mathrm{Tg}$ sulfur dioxide for 1980 .

Probably, the values given by Stoiber et al. [1983, 1987] are minimum values since transformation from $\mathrm{SO}_{2}$ to $\mathrm{SO}_{4}{ }^{2-}$ can take place quite rapidly in the plume, especially in the presence of condensed water. Stoiber et al., based on few filter observations, estimates a $1-10 \%$ bias. Other sulfur species, like $\mathrm{H}_{2} \mathrm{~S}$, seemed to be of minor importance. This, however, may depend on the

Table 2. $\mathrm{SO}_{2}$ Measurements and Their Connection With Plume Size

\begin{tabular}{lr}
\hline Plume Size & $\mathrm{SO}_{2}, \mathrm{t} / \mathrm{d}$ \\
\hline Large & 1.500 \\
Medium & 400 \\
Small & 75 \\
Very small & 15 \\
\hline
\end{tabular}

magma type. $\mathrm{SO}_{2}$ dominates $\mathrm{H}_{2} \mathrm{~S}$ during the ejection of basaltic magmas, while for more viscous magmas (andesitic and dacitic), comparable concentrations of these sulfur species were observed [Matsuno, 1960; Allard, 1983].

Berresheim and Jaeschke [1983] separated four categories of quiescent volcanic degassing. Preeruptive degassing with a timescale of days to weeks is a characteristic intensification of volcanic activity before an explosive eruption, including increased fumarolic activity. Between paroxysmal eruptions the intraeruption phase lasts over hours to days, but sometimes this phase occurs repeatedly. After the explosive activity has ended, the volcano exhibits posteruption activity with permanent fuming and increased fumarolic activity. After this phase for years to centuries the extraeruption activity with fumarolic and solfataric activity continues.

Berresheim and Jaeschke [1983] did not consider the preeruption and intraeruption phases in their estimation of volcanic sulfur sources since they quoted these phases to be too short-lived. Gerlach [1991b], however, only estimated volatiles from these categories and found an annual contribution from intraeruption and preeruption phases of $\sim 60$ volcanos of the order of $13.4 \mathrm{Tg}$ $\mathrm{SO}_{2} / \mathrm{yr}$. This value was determined from measurements at seven volcanos (Volcano, White Island, Redoubt, Kilauea, St. Helens, Augustine, and Mount Etna) which represent the main spectrum of activity and magma types.

Differing from Stoiber et al. [1987] or Gerlach [1991b], Berresheim and Jaeschke [1983] estimated posteruptive (with permanent fuming and fumarolic activity) and extraeruptive (mainly fumarolic and solfatic activity). They considered 365 posteruptive volcanos; $25 \%$ of those emitted $275 \mathrm{t} \mathrm{SO}_{2} / \mathrm{d}$ and $75 \%$ only produce $50 \mathrm{t} \mathrm{SO}_{2} / \mathrm{d}$. This, as a maximum, gives a total of $14 \mathrm{Tg} \mathrm{SO} /$ yr due to posteruptive activity and with another 100 volcanos exhibiting extraeruptive fumarolic activity gives another $0.2 \mathrm{Tg}$.

The posteruptive $\mathrm{SO}_{2}$ emission is partly comparable with Stoiber et al.'s [1987] plume census results of $6.8 \mathrm{Tg} \mathrm{SO} / \mathrm{yr}$. However, he included only 102 known degassing volcanos in his study. This may be considered as the fuming part of the posteruptive volcanos. Fumarolic flank activity, which does not produce a plume, is absent in this estimate. Berresheim and Jaeschke [1983], on the other hand, may have overestimated the number of degassing volcanos. They just take the number of historic eruptions without judging for the real state of activity. In addition to the $\mathrm{SO}_{2}$ emission, Berresheim and Jaeschke [1983] estimated an annual flux of $\mathrm{H}_{2} \mathrm{~S}$ and $\mathrm{SO}_{4}{ }^{2-}$ of the order of $4.2 \mathrm{Tg} \mathrm{S} / \mathrm{yr}$ which is not included in other estimates. Therefore the real emission rate of $\mathrm{SO}_{2}$ by posteruptive and extraeruptive volcanos may be between 6.8 and $14.2 \mathrm{Tg} \mathrm{SO}_{2} / \mathrm{yr}$ with a good compromise being $10 \mathrm{Tg}$ of $\mathrm{SO}_{2} / \mathrm{yr}$

\section{Explosive emission}

While it is already a tough task to estimate the more or less steady quiescent degassing rates of $\mathbf{S}$ compounds from volcanoes, the estimate of the contribution of explosive volcanism is even tougher. There are only a few observations of eruptive emissions of $\mathrm{SO}_{2}$. The most reliable ones come from total ozone mapping spectrometer (TOMS) measurements, which have a detection limit of approximately $20 \mathrm{kt} \mathrm{SO} /$ event. Thus only larger emission events are captured by TOMS. Other measurements come from COSPEC (which can be biased by very dense plumes) and the pet- 
Table 3. $\mathrm{SO}_{2}$ Emissions Based on VEI-SO ${ }_{2}$ Emission Rates From 1975-1985

\begin{tabular}{lrrrr}
\hline & \multicolumn{5}{c}{ VEI } \\
\cline { 2 - 5 } & 0 & 1 & 2 & 3 \\
\hline Number (1975-1985) & 70 & 124 & 125 & 49 \\
Events per year & 0.64 & 11.3 & 11.4 & 4.4 \\
Total $\mathrm{SO}_{2}$ emission (1975-1985), $\mathrm{Tg}$ & 0.7 & 7.44 & 12.5 & 34.4 \\
Median $\mathrm{SO}_{2}$ emission Tg/event & 0.01 & 0.06 & 0.1 & 0.7 \\
\hline
\end{tabular}

VEI, volcanic explosivity index.

rologic method applied to melt inclusion. The latter method is applicable to all kinds of eruptive volcanism, but for the two latest eruptions (El Chichón 1982 and Pinatubo 1991) this method did not correlate with the enormous amounts of $\mathrm{SO}_{2}$ injected into the stratosphere. The reason for this is still under discussion [Gerlach and McGee, 1994]. Anhydrite phenocrystals were found in ash and lapilli of El Chichón and Pinatubo ejecta. Their decomposition during the eruption may be responsible for the $\mathrm{SO}_{2}$ surplus according to Baker and Rutherford [1992]. Another explanation is given by Gerlach and McGee [1994] who underline the importance of enrichment of volatile sulfur during noneruptive phases of the volcano. Bluth et al. [1993] as well as Stoiber et al. [1987] attempted to combine information about volcanic explosivity (volcanic explosivity index (VEI) [Newhall and Self, 1982]) and the $\mathrm{SO}_{2}$ content of the plume. This is, however, a very indirect parameterization, hence leading to a spread of the order of 1.5 magnitudes for the same value of VEI [see, e.g., Stoiber et al., 1987, Figures 1-3]. Therefore any estimate of global explosive emission of $\mathrm{SO}_{2}$ is questionable. The situation becomes even worse when the variability in space and time is considered, since some of the eruptive events last for months and some are as short as 1 day only. Therefore we needed emission rates based on direct continuous measurements. Such data are not yet available, and therefore an order-of-magnitude estimate can only be given here.

Using the information from $M c$ Clelland et al. [1989] there are 67 measurements of the $\mathrm{SO}_{2}$ flux with minimum/median/maximum $\mathrm{SO}_{2}$ emission rates of $20 / 170 / 24,000 \mathrm{t} / \mathrm{d}$. This gives for the median emission rate a total of $\sim 4.1 \mathrm{Tg}$ of $\mathrm{SO}_{2}(\sim 2 \mathrm{Tg}$ of sulfur)/ $\mathrm{yr}$, provided that all 67 sites emitted over the whole time, which, considering the 2 orders of magnitude higher maximum values, seems to be justified.

With the approach of Stoiber et al. [1987] the estimate of VEIsulfur emission ratio yields about $2.5 \mathrm{Tg} \mathrm{S} / \mathrm{yr}$ considering the values in Table 3. For the year of 1980 (1985) the episodic emission of explosive volcanic sources sums up to $1.6(3.8) \mathrm{Tg}$ of sulfur based on the VEI data published by McClelland et al. [1989]. Thus about $2 \mathrm{Tg}$ of explosively emitted sulfur may count as a relarively conservative estimate. This is much less than the $4.35 \mathrm{Tg} / \mathrm{yr}$ suggested by Stoiber et al. [1987] for troposphere injection, excluding VEI greater than or equal to four events. We therefore propose a value of $4 \mathrm{Tg} S / \mathrm{yr}$ to be emitted by explosive volcanism with error margins of about $\pm 2 \mathrm{Tg} S$.

\section{Total Emission}

The total emission of sulfur dioxide in sulfur units to the troposphere from volcanic sources is given in an order of magnitude estimate in Table 4 . These values are subject to large temporal and spatial variations, since volcanic activity varies. Singular events, like the Laki eruption from 1783-1784 can produce magnitudes higher emissions. Thordarson and Self [1993] give a value of 115 $\mathrm{Tg} \mathrm{SO}$ that remained in the troposphere and were removed as fallout and acid rain during summer and fall 1783. The Laki eruption rates following Thordarson and Self [1993] were 0.5-1.5 Tg of $\mathrm{SO}_{2} / \mathrm{d}$. Such events, however, are rare and cannot be included in an estimate of the "background" volcanic sulfur source. Also not considered is the impact of paroxysmal eruptions which also have to be considered as singular events. The (subjective) estimated accuracy in Table 4 therefore is only valid for the background emissions and describes their uncertainty. In addition to this uncertainty of the global budget the variability in space and time has to be considered. Our "best estimate" of global mean volcanic sulfur emission is at $14 \pm 6 \mathrm{Tg} \mathrm{S} / \mathrm{yr}$. This value is used in the current model study. The lower limit of our estimate corresponds to the value suggested by Bluth et al. [1993] . Lambert et al. [1988] estimated the global volcanic annual Polonium release rate and suggested assuming a fixed $\mathrm{SO}_{2} /$ Po ratio an upper limit of volcanic sulfur emissions of $25 \mathrm{Tg} \mathrm{S} / \mathrm{yr}$.

\section{Model Experiments}

To study the contribution of the volcanic sulfur emissions to the global atmospheric sulfate load, we performed an experiment with a coupled atmospheric circulation-chemistry model. Transport, dry and wet deposition, and chemical interactions of the chemical constituents are calculated on-line in a climate circulation model, the Hamburg climate model European Centre Hamburg (ECHAM) [Roeckner et al., 1992] . The model treats three sulfur species as prognostic variables: dimethylsulfide and sulfur dioxide as gases and sulfate as aerosol. To estimate the contribution from the various source types, we calculate not only the transport of total $\mathrm{SO}_{2}$ and $\mathrm{SO}_{4}{ }^{2-}$ but additionally the ratio between the contribution from a specific source to the total sulfur budget. In the current study we use the version ECHAM4 with a T30 resolution denoting a triangular truncation at wavenumber 30 of the spectral harmonic representation of the model variables. Nonlin-

Table 4. Estimate of Volcanic Sulfur Sources for the Troposphere

\begin{tabular}{lc}
\hline Phase of Activity & Emission S, Tg/yr \\
\hline Preeruption and intraeruption & $5 \pm 2$ \\
Posteruption and extraeruption & $5 \pm 2$ \\
Explosive & $4 \pm 2$ \\
Total & $14 \pm 6$ \\
\hline
\end{tabular}


Table 5. Global and Hemispheric Sulfur Sources

\begin{tabular}{lrrrrr}
\hline & $\begin{array}{r}\text { Marine and } \\
\text { Terrestrial } \\
\mathrm{DMS}\end{array}$ & $\begin{array}{r}\text { Volcanic } \\
\mathrm{SO}_{2}\end{array}$ & $\begin{array}{r}\text { Biomass } \\
\text { Buming }\end{array}$ & $\begin{array}{r}\text { Fossil Fuel } \\
\text { Use and } \\
\text { Industry }\end{array}$ & Total \\
\hline Northem hemisphere & 7.5 & 10.0 & 1.0 & 60.5 & 79.0 \\
Southem hemisphere & 11.0 & 4.0 & 1.5 & 6.3 & 22.8 \\
Global & 18.5 & 14.0 & 2.5 & 66.8 & 101.8 \\
\hline
\end{tabular}

Sulfur sources are in teragrams per year.

ear terms and physical processes are evaluated at grid points of a "Gaussian" grid providing a nominal resolution of $3.75^{\circ}$ in latitude and longitude. The model uses a hybrid coordinate system with 19 vertical levels ranging from the surface up to $10 \mathrm{hPa}$. The temporal finite difference scheme is semiimplicit with a time step of $30 \mathrm{~min}$.

Positive definite quantities like water vapor, cloud liquid water and chemical species are advected using a semi-Lagrangian scheme [Rasch and Williamson, 1990] . Surface fluxes of momentum, heat, moisture, and chemical tracers are calculated from Monin-Obukhov theory. Within the boundary layer and also in the free atmosphere, turbulent transfer is calculated on the basis of a higher-order closure scheme [Brinkop and Roeckner, 1995] . Vertical fluxes in convective clouds are calculated using the mass flux scheme developed by Tiedtke [1989] and modified by Nordeng [1996] which treats penetrative, shallow, and midlevel convection. This bulk cumulus ensemble model considers updraft and downdraft mass fluxes, as well as organized and turbulent entrainment and detrainment. The cloud water amount is a prognostic variable in ECHAM, and the fractional cloud cover within a grid square is parameterized as a function of the relative humidity [Sundquist, 1978; Roeckner, 1995].

All biogenic emissions from the ocean, soils, and plants are assumed to occur as DMS, whereas volcanic and anthropogenic emissions are assumed to occur as $\mathrm{SO}_{2}$. Monthly mean terrestrial biogenic emissions are taken from a database compiled by Spiro et al. [1992] and sum up to $0.9 \mathrm{Tg}$ S/yr. Oceanic DMS emissions are calculated by latitudinally averaged DMS concentrations in the sea surface water. These concentrations, based on data by Bates et al. [1987], only differentiate between winter and summer conditions. The air-sea gas exchange can then be calculated with piston velocities, derived from the model $10-\mathrm{m}$ wind speed and sea surface temperature following Liss and Merlivat [1986]. We compute a global annual emission of $17.6 \mathrm{Tg}$ sulfur. The two anthropogenic sulfur sources considered in this study are biomass buming and fossil fuel combustion. Both are assumed to exclusively emit $\mathrm{SO}_{2}$. Sulfur emissions from biomass burning are distributed according to Hao et al. [1990] assuming an emission of $2.5 \mathrm{Tg} \mathrm{S} / \mathrm{yr}$, following Langner et al. [1992] . Sulfur emissions from fossil fuel combustion and industrial processes are taken from the inventory of Benkovitz et al. [1994], representative for the year $1985(66.8 \mathrm{Tg}$ $\mathrm{S} / \mathrm{yr}$ ). We release the industrial emissions as well as the emissions from biomass buming either at the surface or in the next higher level (about $110 \mathrm{~m}$ ) according to Benkovitz et al. [1994] . Global sulfur emissions from all the sources amounts to $101.8 \mathrm{Tg}$ sulfur (Table 5).

The following chemical reactions are taken into account. DMS as well as $\mathrm{SO}_{2}$ in the gaseous phase are oxidized by reaction with hydroxyl radicals $(\mathrm{OH})$ during the day. DMS reacts additionally with nitrate radicals $\left(\mathrm{NO}_{3}\right)$ at night. We have assumed that the only end product of DMS oxidation is $\mathrm{SO}_{2}$. In the aqueous phase we consider oxidation of $\mathrm{SO}_{2}$ by hydrogen peroxide $\left(\mathrm{H}_{2} \mathrm{O}_{2}\right)$ and ozone $\left(\mathrm{O}_{3}\right)$. The calculation of the reaction rates and the dissolution and dissociation rates of $\mathrm{SO}_{2}$ require assumptions about the cloud water $p \mathrm{H}$. Hence we estimate diagnostically the cloud water $p \mathrm{H}$ depending on the sulfate concentrations. The end product of the gaseous and the aqueous oxidation of $\mathrm{SO}_{2}$ is sulfate (for a more detailed description, see Feichter et al. [1996]. After a 3month spin-up time we integrated the model over 5 years prescribing a monthly mean climatology of the sea surface temperatures.

\section{Model Results of the Sulfur Budget}

\section{Global Budgets}

Table 6 shows the annually and globally averaged $\mathrm{SO}_{2}$ and $\mathrm{SO}_{4}{ }^{2-}$ vertical columns and the sulfur deposition by rain as well as

Table 6. Global and Annual Mean Sulfur Budgets and Emission and Wet Deposition Fluxes

\begin{tabular}{lccccc}
\hline & $\begin{array}{c}\text { Sulfur } \\
\text { Emission }\end{array}$ & $\begin{array}{c}\mathrm{SO}_{2} \\
\text { Burden }\end{array}$ & $\begin{array}{c}\mathrm{SO}_{4}{ }^{2-} \\
\text { Burden }\end{array}$ & $\begin{array}{c}\text { Sulfur Wet } \\
\text { Deposition }\end{array}$ & Efficiency \\
\hline Total, Tg S/yr & 101.8 & 0.52 & 0.78 & 61.7 & -- \\
& Contribution of the Specific Sources to the Total Budgets, \% & & \\
Anthropogenic & 65.6 & 46.1 & 37.1 & 1.4 & 0.56 \\
Biomass buming & 2.5 & 1.2 & 1.6 & 28.6 & 1.39 \\
DMS & 18.2 & 17.8 & 25.3 & 29.6 & 2.63 \\
Volcanoes & 13.7 & 34.9 & 36.0 & & 0.64 \\
\hline
\end{tabular}

Sulfur budgets and emission and wet deposition fluxes are in teragrams per year. Contributions from the different sources are given in percent of the total budgets. Efficiency is defined as the fractional contribution to the sulfate burden divided by the fractional source strength. 

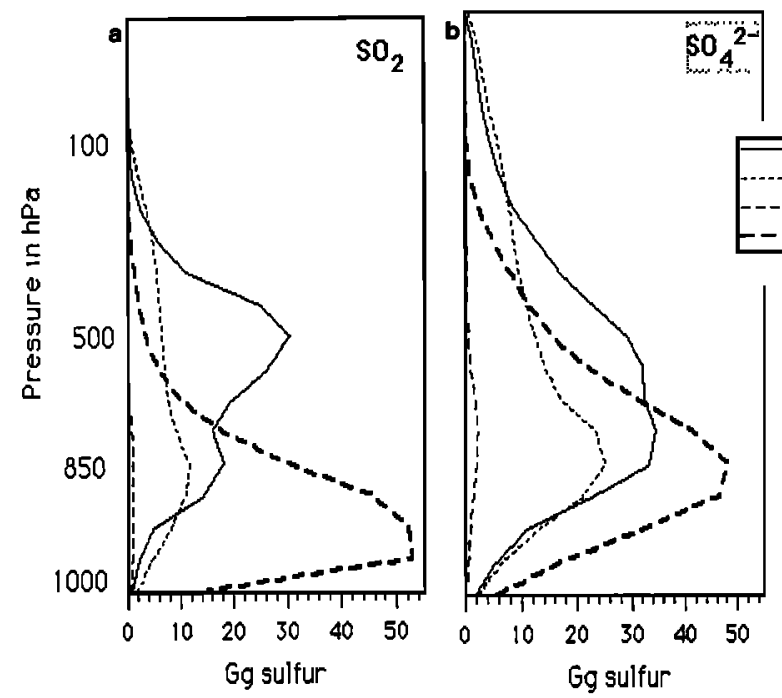

Figure 2. Global annual mean vertical profile of (a) (left panel) $\mathrm{SO}_{2}$ and (b) (right panel) $\mathrm{SO}_{4}{ }^{2-}$ burden from various sources.

the fractional contributions from the different source types. The global $\mathrm{SO}_{2}$ burden is with $0.52 \mathrm{Tg} \mathrm{S}$ higher than other estimations. Langner et al. [1992] (L91) report a SO $\mathrm{S}_{2}$ burden of $0.30 \mathrm{Tg} \mathrm{S}$ for their fast oxidation case and $0.47 \mathrm{Tg}$ S for the slow oxidation case; Pham et al. [1995] (P95) give a value of $0.2 \mathrm{Tg} \mathrm{S}$; Chin et al. [1996] (C96) give a value of $0.34 \mathrm{Tg} \mathrm{S}$, and Feichter et al. [1996] obtained, using the same meteorological and chemical model but assuming lower volcanic emissions (3.5 compared with $14 \mathrm{Tg} \mathrm{S} /$ $\mathrm{yr}$ ), a value of $0.44 \mathrm{Tg}$ S. Obviously, $\mathrm{SO}_{2}$ released from volcanoes into higher altitudes has a longer atmospheric residence time mainly due to a lower dry deposition rate. Hence only $36 \%$ of all $\mathrm{SO}_{2}$ emissions are removed by dry and wet deposition, and $64 \%$ are transformed to sulfate, whereas this transformation rate reported in the studies cited above is between 50 and $55 \%$.

The vertical sulfate column is $0.78 \mathrm{Tg} S$ which is in the range reported by previous studies $(0.53 \mathrm{Tg} \mathrm{S} \mathrm{C96,0.80} \mathrm{P95).} \mathrm{Sixty-one}$ percent of the total sulfur amount is removed by rain, and $39 \%$ is removed by dry deposition, preferably as $\mathrm{SO}_{2}$. The most striking feature is that the contributions of the different sources to the $\mathrm{SO}_{2}$ as well as to the sulfate burden are not linear with respect to their source strengths. Although volcanic emissions amount only to about $14 \%$ of total emissions, they contribute $35 \%$ to the $\mathrm{SO}_{2}$ bur-

den and $36 \%$ to the $\mathrm{SO}_{4}{ }^{2-}$ burden. The fraction of $\mathrm{SO}_{2}$ produced by DMS oxidation is proportional to the DMS source strength, but it contributes more efficiently to the sulfate load, whereas sulfur from fossil fuel combustion and from biomass buming is obviously not as efficiently transformed to sulfate. If we define the efficiency with which a specific source contributes to the sulfate load as the ratio between fractional contribution to the sulfate burden divided by the contribution to the total emission, the efficiency is highest (2.63) for volcanic sulfur emissions and lowest (0.56) for anthropogenic emissions. The contribution of volcanic emissions to the acid rain is not as efficient as to the sulfate load but is also higher than expected from the corresponding source strengths.

\section{Vertical Distribution}

Figure 2 shows the annually and globally averaged vertical distribution of $\mathrm{SO}_{2}$ and $\mathrm{SO}_{4}{ }^{2-}$. $\mathrm{SO}_{2}$ from anthropogenic sources dom- inates below $700 \mathrm{hPa}$ with a distinctly marked maximum near the ground. The vertical distribution of volcanic $\mathrm{SO}_{2}$ shows two maxima, one in $850 \mathrm{hPa}$ due to preeruptive and intraeruptive emissions and a stronger one in $500 \mathrm{hPa}$ due to explosive activity. The vertical distribution of sulfate formed from volcanic $\mathrm{SO}_{2}$ has a maximum in $800 \mathrm{hPa}$, and volcanic sulfate dominates between 700 and $200 \mathrm{hPa}$. This may have an important influence on the efficiency with which short wave radiation is backscattered to space since sulfate particles in higher altitudes are not shielded by clouds. Sulfate aerosols also exert an influence on the optical properties of clouds. Aerosols serve as cloud condensation nuclei (CCN), and an increase in $\mathrm{CCN}$ enhances the cloud number droplet concentration (Twomey effect). Platnick and Twomey [1994] report, based on satellite observations, a higher cloud susceptibility, defined as the influence of $\mathrm{CCN}$ number concentrations on cloud albedo, in marine stratus clouds. The contribution of volcanoes to this indirect effect is difficult to estimate as sulfate aerosols from volcanic emissions are present at higher altitudes and are therefore only partly cycled within clouds. On the other hand, the sulfate plumes of volcanic emissions cover large parts of the tropical and subtropical oceans where the sulfate load from other sources is low and the susceptibility of clouds is high.

\section{Reglonal Distributions}

Within the boundary layer, sulfate formed from anthropogenic sulfur sources is distinctly higher than contributions from other sources. In Figure 3 the volcanic fraction of the annual mean $\mathrm{SO}_{2}$ and $\mathrm{SO}_{4}{ }^{2-}$ surface concentration is plotted in percent. Because of the rather low turnover time of $\mathrm{SO}_{2}$ of 1.8 days and the fact that a large fraction of the volcanic emissions is released into higher altitudes, the volcanic contributions to the surface $\mathrm{SO}_{2}$ concentrations are quite low ( $12 \%$ globally) except very close to the sources. The volcanic contribution to the sulfate surface concentration is somewhat higher ( $21 \%$ globally), but again a higher contribution is only found near the sources. In particular, in continental midlatitudes where most observations are available the volcanic contribution is lower than $10 \%$. Therefore, one cannot expect to detect the volcanic contribution to the $\mathrm{SO}_{2}$ and $\mathrm{SO}_{4}{ }^{2-}$ surface concentrations 

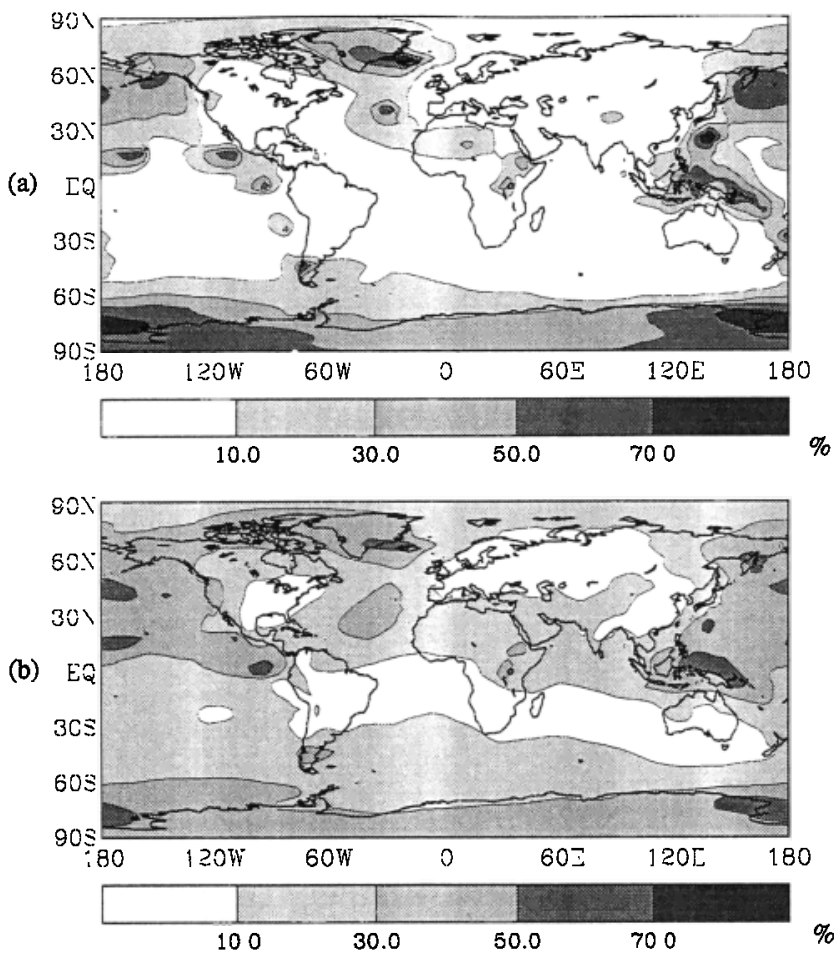

Figure 3. Annual mean (a) $\mathrm{SO}_{2}$ and (b) $\mathrm{SO}_{4}{ }^{2-}$ surface concentration due to volcanic emission in percent of the total concentrations.

in these observations. The situation is somewhat better in polar latitudes where volcanic emissions contribute between 30 and $50 \%$ to the total $\mathrm{SO}_{2}$ and $\mathrm{SO}_{4}{ }^{2-}$ concentrations.

In polar regions, however, the typical high concentration of sulfate in winter and spring (arctic haze) is not reproduced by the model. Probably, the boundary layer transport of sulfur compounds both from anthropogenic as well as from natural sources is not adequately simulated by the circulation model. This question deserves further investigation.

The annual and global mean contribution to the wet deposition flux from volcanic sources amounts to about 30\% (see Table 6). However, the total sulfur deposition flux is higher than $500 \mathrm{mg} / \mathrm{m}^{2}$ only in regions with high anthropogenic emissions, that is, eastern United States, Europe, and southeast Asia (Figure 4a) where volcanic contributions are low (Figure $4 b$ ). The only region where we find high deposition fluxes as well as significant volcanic contributions is Malaysia and Indonesia. Unfortunately, no observations are available in this region. Generally, surface observations are not well suited for the detection of the volcanic impact on the atmospheric sulfur budget. Since measurements in the free atmosphere are not yet available, our model results cannot be directly evaluated.

In spite of the weak volcanic signal at the surface, volcanic emissions contribute significantly to the global sulfate burden ( $36 \%$ globally). Figure 5 shows the annual mean vertical sulfate column and the volcanic contribution. We find similar to the distribution of the wet deposition the highest sulfate burden over industrialized regions and quite low values in the $\mathrm{SH}$, particularly over the oceans. If we compare our sulfate burden with an experiment performed with the same meteorological and chemical model [Feichter et al., 1996] but with much lower volcanic emissions (3.5 compared with $14 \mathrm{Tg} \mathrm{S} / \mathrm{yr}$ ), the most obvious change is an increase of the sulfate burden over remote areas. Whereas the
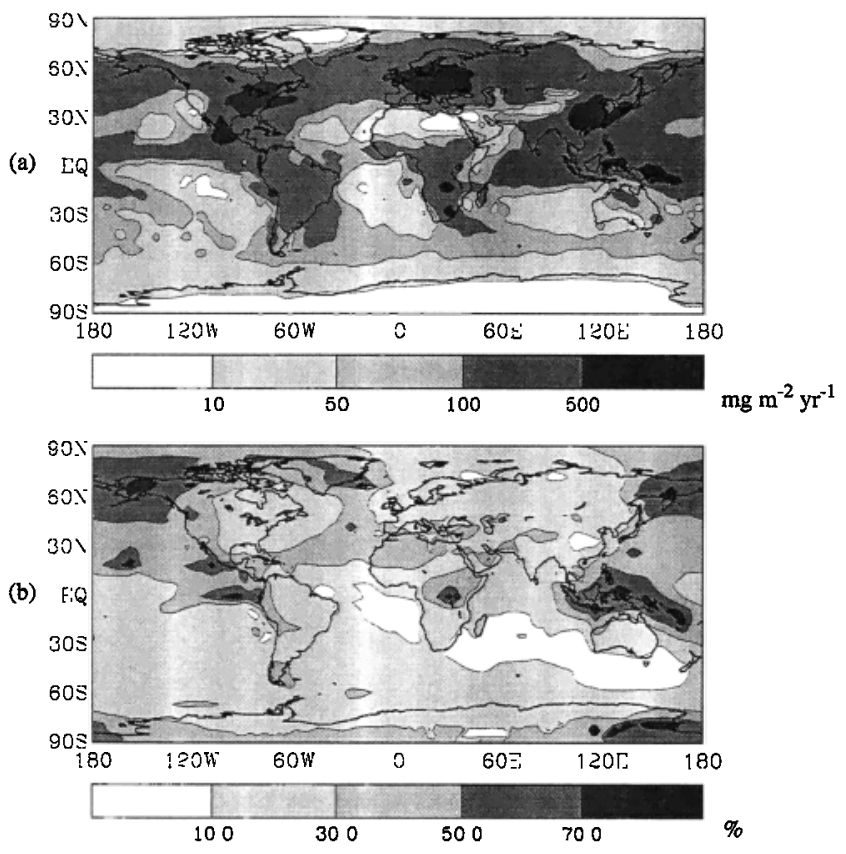

Figure 4. (a) Annual mean wet deposition of sulfur (in milligrams per square meter per year) and (b) contribution due to volcanic emissions in percent.

maxima are in the same order and at the same geographical locations, values in the SH and at high latitudes of the $\mathrm{NH}$ have increased by a factor of 2 . The strongest increase by about a factor of 5 is found over the Indian Ocean and over Indonesia. Volcanic emissions contribute by more than $50 \%$ over large parts of the $\mathrm{NH}$ Pacific, at high latitudes over North America, and in the tropics west of South America and over the Indian Ocean and Indonesia.
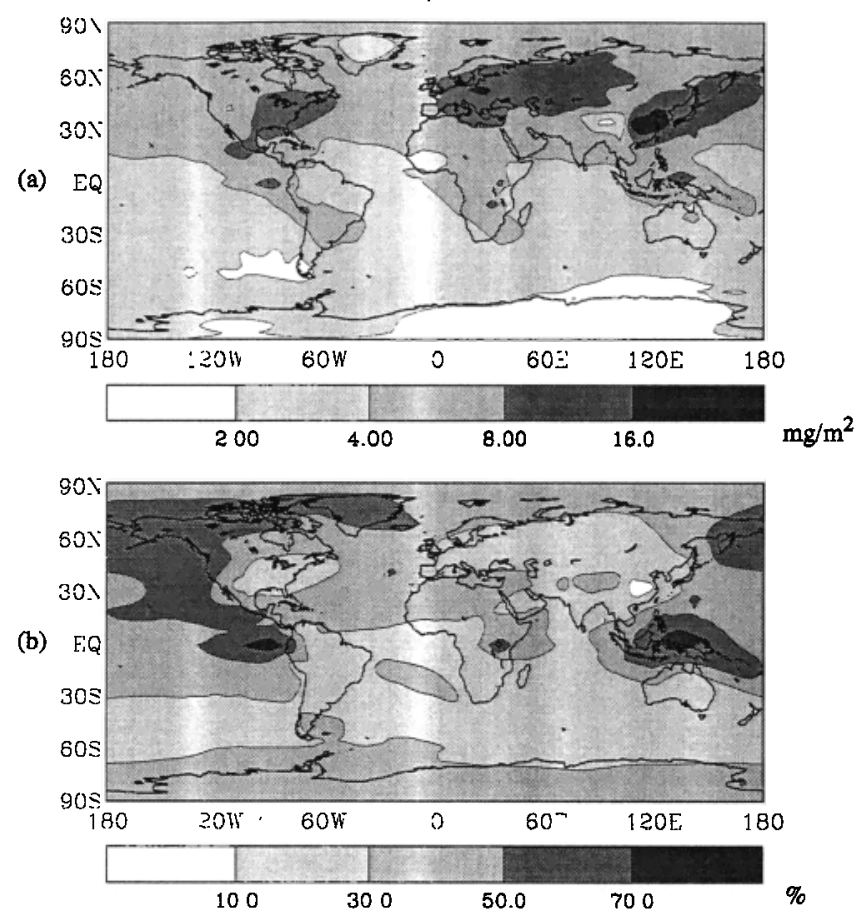

Figure 5. (a) Annual mean vertical sulfate burden (in milligrams per square meter) and (b) the contribution due to volcanic emission in percent. 
Table 7. Total Annual Mean Direct Radiative TOA Forcing Including the Effect of Relative Humidity of Ambient Air and Percentage of the Different Sources

\begin{tabular}{lrrr}
\hline & Global & Northem Hemisphere & Southem Hemisphere \\
\hline Total direct forcing W/m ${ }^{2}$ & -0.65 & -0.89 & -0.41 \\
Anthropogenic, \% & 39.6 & 47.1 & 23.1 \\
Volcanic, \% & 32.9 & 35.1 & 27.9 \\
DMS, \% & 25.8 & 16.7 & 45.8 \\
Biomass, \% & 1.7 & 1.1 & 3.2 \\
\hline
\end{tabular}

TOA, top of atmosphere.

\section{Radiative forcing}

\section{Diagnostic Tools}

The direct and indirect radiative forcing of sulfate aerosols from different sources is determined using a new off-line analysis tool [Langmann et al., 1997]. This diagnosis scheme was developed in order to estimate the radiative impact of aerosols, including cloud elements, in a very efficient computational way. For the short wave part of the solar spectrum $(0.2-5.0 \mu \mathrm{m})$ the $\delta$-Eddington approximation is applied for a set of 18 wavelength intervals. Unequal spectral interval length as well as spectral data for important absorbers (ozone, water vapor, oxygen, and carbon dioxide) and scatterers, in particular clouds, is taken from Briegleb [1992]. This parameterization explicitly related cloud radiative properties to the cloud droplet properties (liquid water path and effective radius). The long wave effect of sulfate aerosols is not considered here as we only look at the solar radiative forcing.

Optical properties of the dry sulfate aerosol were determined by I. Schult (personal communication, 1996), from Mie theory calculations, assuming a zero order logarithmic size distribution with a mean particle radius of $0.05 \mu \mathrm{m}$ and a geometric standard deviation of 1.8. In addition, the particle density was set to 1.6 $\mathrm{gcm}^{-3}$ for an aerosol mixture of $75 \% \mathrm{H}_{2} \mathrm{SO}_{4}$ and $25 \% \mathrm{H}_{2} \mathrm{O}$. The resulting wavelength dependent values for specific extinction, single scattering albedo, and asymmetry parameter agree almost perfectly with the data given by Kiehl and Briegleb [1993], except the specific extinction for wavelengths smaller than $1.0 \mu \mathrm{m}$ (our estimate is about 0.75 times the specific extinction based on Kiehl and Briegleb [1993]). In order to consider the modifications of the aerosol specific extinction due to the influence of the relative humidity of the ambient air we use a simple approximation adopted from the data given by Nemesure et al. [1995]. Relating aerosol specific extinction at $80 \%$ relative humidity to $50 \%$ results in a factor 1.6, which is in good agreement with the relative humidity factor 1.7 determined by Charlson et al. [1991] .

The indirect radiative forcing of sulfate aerosols is determined from an empirical relationship between sulfate aerosol mass concentration and cloud droplet number concentration (CDNC) [Boucher and Lohmann, 1995, relationship D]. CDNC is then related to the droplet effective radius. Thus varying cloud radii are

(a)
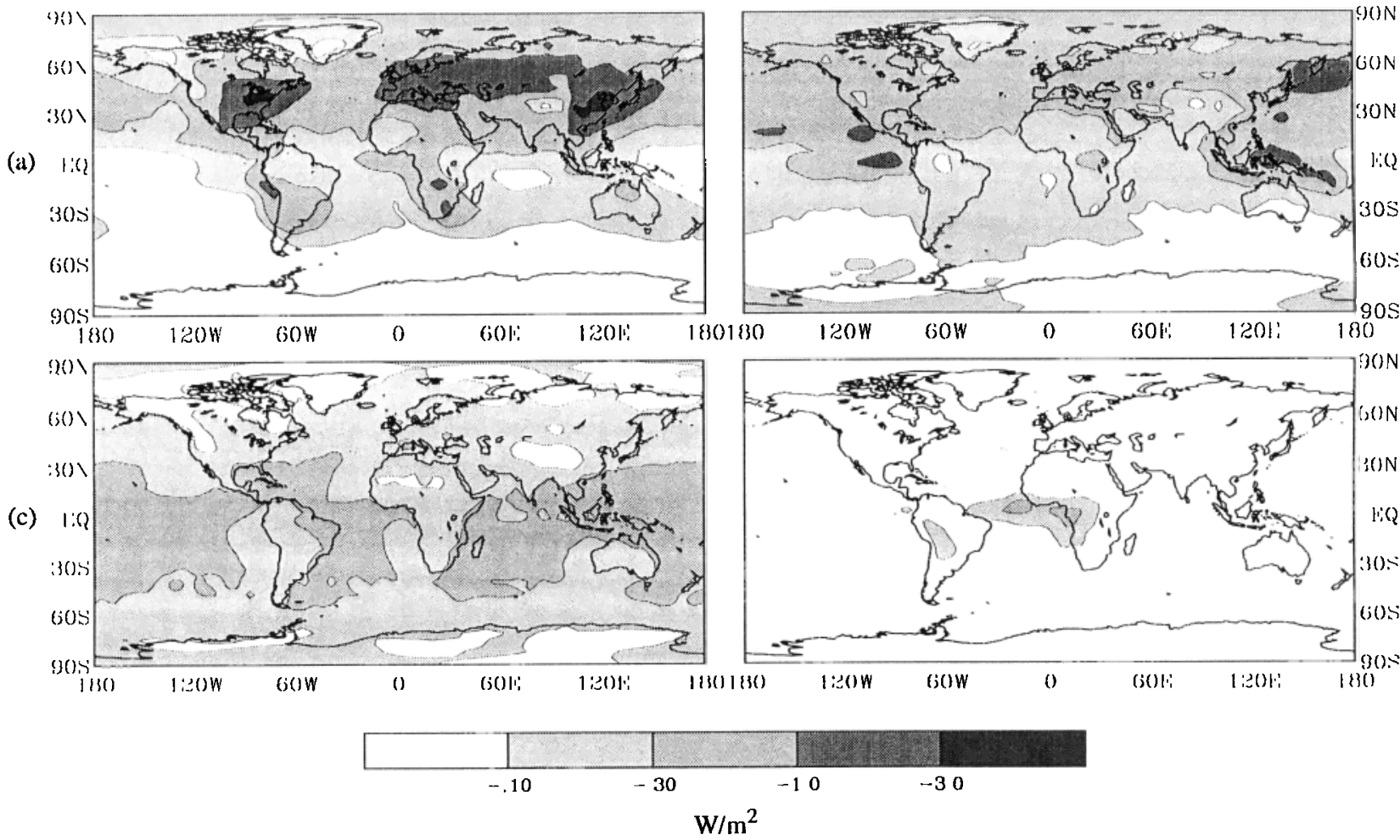

Figure 6. Direct annual mean short wave radiative forcing (in watts per square meter) due to (a) anthropogenic, (b) volcanic, (c) DMS and (d) sulfate due to biomass burning. 
explicitly used to estimate the indirect effect of sulfate aerosols on cloud reflectance. As the analysis of the radiative forcing is based on monthly mean fields of humidity, cloudiness, and sulfate concentration, any feedback to cloud properties (i.e., longer lifetime of cloud droplets) and, consequently, faster formation of sulfate in a more cloudy and humid atmosphere is neglected. It should also be mentioned that for indirect forcing the total sulfate effect is unknown (i.e., we do not know how clouds behave without any CDNC in the atmosphere). Thus the single effects were simply checked by subtraction of the respective sulfur source from total sulfate and have only a relative meaning.

\section{Direct Radiative Forcing Results}

Our estimate of the global annual mean direct forcing for anthropogenic sulfate aerosol $\left(-0.26 \mathrm{~W} / \mathrm{m}^{2} ; 39.6 \%\right.$ of the total of $-0.65 \mathrm{~W} / \mathrm{m}^{2}$, Table 7) agrees best with Kiehl and Briegleb [1993] $\left(-0.28 \mathrm{~W} / \mathrm{m}^{2}\right)$. For anthropogenic plus natural sulfate aerosols, Kiehl and Briegleb [1993] calculate a global annual mean direct forcing of $-0.54 \mathrm{~W} / \mathrm{m}^{2}$; here a forcing of $-0.65 \mathrm{~W} / \mathrm{m}^{2}$ is obtained. This difference may be attributed to volcanic sulfate, as other studies are assuming lower volcanic emissions [Langner et al., 1992; Feichter et al., 1996).

Generally, in the annual and global mean, anthropogenic, volcanic, and DMS products have a comparable direct (Table 7) impact on solar radiation. The anthropogenic contribution to the total effect is about $7 \%$ larger than the volcanic, which again is $7 \%$ above that of the DMS sources. Sulfate from biomass burning is neglectible for the radiative forcing (Figure 6). It has some influence, however, in areas of otherwise less sulfate concentration like, for example, parts of tropical West Africa, the Gulf of Guine, and tropical South America. Becausse of the emission structure, anthropogenic sulfate effects dominate the NH throughout the year, while DMS products have their strongest radiative effects in austral summer on the SH, where they make up about $50 \%$ of the total forcing. The changes of volcanic sulfate radiative forcing are comparably small both during the annual cycle and over the hemisphere. If the influence of ambient air humidity on the optical parameters of sulfate aerosol is not taken into account, the total forcing decreases by a factor of about 2 .

\section{Indirect Radiative Forcing Results}

The indirect radiative forcing (Figure 7) via the modification of the optical properties of clouds in general is at least as large as the direct effect. Generally, it is even stronger. It is thus important to improve our basic knowledge of this impact factor. As already mentioned, the relative contributions of the single sulfate sources to cloud reflectivity are determined by subtraction of the respective sulfur source from total sulfur. Therefore, in some regions, saturation effects occur. For a constant liquid water path a maximum of backscattering of solar radiation by cloud droplets is already reached by a specific sulfate mass concentration, which is frequently less than the total sulfate mass. Thus our estimate for the indirect effect of anthropogenic sulfate is smaller compared to Boucher and Lohmann [1995]. Especially, in the NH the higher amount of volcanic sulfate obtained in our computations competes with anthropogenic sulfate in modifying cloud droplet properties.

It is interesting to note that in case of higher natural sources of sulfate the anthropogenic impact on the short wave radiation due to additional sulfate particles may be diminished. The indirect radiative effects are less homogeneously distributed than direct effects. In cloud-free areas, of course, there is no effect, but cloudrich areas are especially affected. Volcanic and DMS emissions are especially effective in rural and maritime areas, particularly in midlatitudes of the SH. There the strongest reductions of solar radiation are found, which, locally, can reach several watts per square meter.

\section{Conclusions}

Weakly explosive and quiet volcanoes and other natural sulfur species emissions play a greater role in the atmospheric sulfur cycle and in radiative forcing than one would expect from the emission inventories. A global circulation model, coupled to a sulfur chemistry scheme, was used to trace the origin of sulfate in the atmosphere. If the model is forced by common anthropogenic and DMS emissions in addition to a conservative volcanic source of 14 $\pm 6 \mathrm{Tg} \mathrm{S} / \mathrm{yr}$, which spatially is distributed like the volcanic activity of the year 1985, the resulting sulfate burden and radiative forcing of volcanic origin is comparable with the anthropogenic and is somewhat larger than the DMS-originated sulfate burden. The role of biomass burning is neglectable in this respect. The model study has shown that there are strong interhemispheric and seasonal dif-
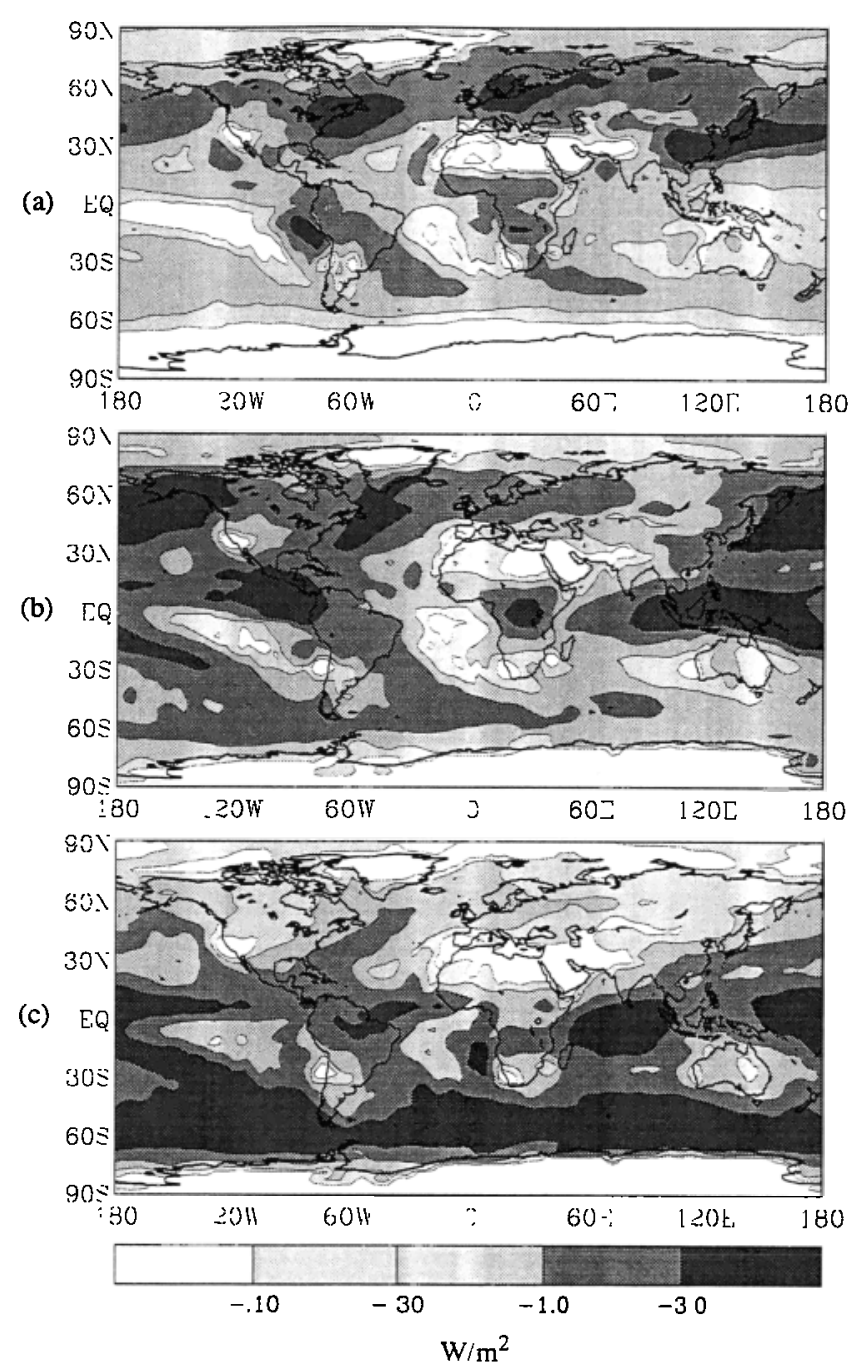

Figure 7. Indirect annual mean radiative forcing (in watts per square meter) due to the aerosol-cloud microphysics effect for (a) anthropogenic, (b) volcanic and (c) DMS sulfate aerosol sources. 
ferences in the relevance of the different sulfur sources. Therefore more detailed studies of the time-space variability of volcanic and biogenic (DMS) sulfur emissions are necessary in order to achieve a more detailed estimate and interpretation of the evolving emission patterns of anthropogenic $\mathrm{SO}_{2}$.

The estimates of solar backscattering on the basis of optical properties of a $\mathrm{H}_{2} \mathrm{O} / \mathrm{H}_{2} \mathrm{SO}_{4}$ mixture are reasonable for the volcanic source, which is located at higher altitudes in an otherwise mostly unpolluted atmosphere. For the other sulfate sources, interactions with other components (sea salt for DMS-generated sulfate, ammonia for anthropogenic sulfate) and modifications of the optical properties have been ignored but should be considered in future studies.

\section{References}

Allard, P., The origin of hydrogen, carbon, sulphur, nitrogen and rare gases in volcanic exhalations: Evidence from isotope geochemistry, in Forecasting Volcanic Events, edited by H. Tazieff and J. C. Sabroux, pp. 337-386, Elsevier, New York, 1983.

Allard, P., J. le Bronec, R. Faivre-Pierret, P. Morel, M.C. Robe, C. Roussel, C. Vavasseut, and P. Zettwoog, Geochemistry of soil gas emanations from Etna, Sicily (abstract), Terra Cognita, 7(2), 407, 1987.

Allard, P., et al., Eruptive and diffusive emissions of $\mathrm{CO}_{2}$ from Mount Etna, Nalure, 351, 387-391, 1991.

Allard, P., J. Carbonnelle, N. Métrich, H. Loyer, and P. Zettwoog, Sulphur output and magma degassing budget of Stromboli volcano, Nature, $368,326-330,1994$.

Andres, R. J., J. Barquero, and W. I. Rose, New measurements of $\mathrm{SO}_{2}$ flux at Poás Volcano, Costa Rica, J. Volcanol. Geotherm. Res., 49, 175-177, 1992.

Baker, L., and M. J. Rutherford, Anhydrite breakdown as a possible source of excess sulfur in the 1991 Mount Pinatubo eruption (abstract), Eos Trans. AGU, 73(43), Fall Meet. Suppl, 625, 1992.

Bates, T. S., J. D. Cline, R. H. Gammon, and S. R. Kelly-Hansen, Regional and seasonal variations in the flux of oceanic dimethylsulfide to the atmosphere, J. Geophys. Res., 92, 2930-2938, 1987.

Benkovitz, C. M., C. M. Berkowitz, R. C. Easter, S. Nemesure, R. Wagener, and S. E. Schwartz, Sulfate over the north Atlantic and adjacent continental regions: Evaluation for October and November 1986 using a three-dimensional model driven by observation-derived meteorology. J. Geophys. Res., 99, 20,725-20,756, 1994.

Berresheim, H., and W. Jaeschke, The contributions of volcanoes to the global atmospheric sulfur budget, J. Geophys Res., 88, 3732-3740, 1983.

Bluth, G.J., C.C. Schnetzler, A.J. Krueger, and L.S. Walter, The contribution of explosive volcanism to global atmosphere sulphur dioxide concentrations, Nature, 366, 327-329, 1993.

Boucher, O., and U. Lohmann, The sulfate-CCN-cloud albedo effect, a sensitivity study with two general circulation models, Tellus, Ser. B, 47, 281-300, 1995.

Briegleb, B. P. Delta-Eddington approximation for solar radiation in the NCAR community climate model, J. Geophys. Res., 97, 7603-7612, 1992.

Brinkop, S., and E. Roeckner, Sensitivity of a general circulation model to parameterizations of cloud-turbulence interactions in the atmospheric boundary layer, Tellus, Ser. A, 47, 197-220, 1995.

Charison, R. J., J. Langner, H. Rodhe, C. B. Leovy, and S. G. Warren, Perturbation of the northem hemisphere radiative balance by backscattering from anthropogenic sulfate aerosols, Tellus, Ser. B, 43, 152-163, 1991.

Chin, M., D. J. Jacob, G. M. Gardner, M. Foreman-Fowler, and P. S. Spiro, A global three-dimensional model of tropospheric sulfate, J. Geophys. Res., 101, 18,667-18,690, 1996.

Feichter, J. , E. Kjellström, H. Rodhe, F. Dentener, J. Lelieveld, and G.-J. Roelofs, Simulation of the tropospheric sulfur cycle in a global climate model, Atmos. Environ., in press, 1996.
Gerlach, T. M., Etna's greenhouse pump, Nature, 351, 352-353, 1991 a.

Gerlach, T. M., Present-day $\mathrm{CO}_{2}$ emissions from volcanoes, EoS Trans. $A G U, 72(23), 249-255,1991 \mathrm{~b}$.

Gerlach, T. M., and K. A. McGee, Total sulfur dioxide emissions and preeruption vapor-saturated magma at Mount St. Helens, 1980-1988, Geophys. Res. Lett., 21, 2833-2836, 1994.

Graf, H.-F., I. Kirchner, A. Robock, and I. Schult, Pinatubo eruption winter climate effects: Model versus observations, Clim. Dyn., 7, 81-93, 1993.

Greenland, L. P., Gas emission of the January 1983 eruption of Kilauea volcano, Hawaii, Geochim. Cosmochim. Acta, 48, 193-195, 1984.

Greenland, L. P., W. I. Rose, and J. B. Stokes, An estimate of gas emissions and magmatic gas content from Kilauea volcano, Geochim. Cosmochim. Acta, 49, 125, 1985.

Hansen, J., A. Laci, R. Ruedy, and M. Sato, Potential climate impact of Mt. Pinatubo eruption, Geophys. Res. Lett., 19, 215-218, 1992.

Hao, W. M., M. H. Liu, and P. J. Crutzen, Estimates of annual and regional releases of $\mathrm{CO}_{2}$ and other trace gases to the atmosphere from fires in the tropics, based on the FAO statistics for the period 1975-1980, in Fire in the Tropical Biota, Ecol. Stud., vol. 84, edited by J. G. Goldammer, pp. 440-462, Springer-Verlag, New York, 1990.

Hinkley, T. K., Rock forming metals and $\mathrm{Pb}$ in modem Alaska snow, $J$. Geophys. Res., 98, 20,537-20,545, 1993.

Kiehl, J. T., and B. P. Briegleb, The relative roles of sulfate aerosols and greenhouse gases in climate forcing, Science, 260, 311-314, 1993.

Lambert, G., M.-F. LeCloarec, and M. Pennisi, Volcanic output of $\mathrm{SO}^{2}$ and trace metals: A new approach, Geochim. Cosmochim. Acta, 52, 39-42, 1988.

Langmann, B., M. Herzog, and H.-F. Graf, Radiative forcing of sulfate aerosols as determined by a regional circulation-chemistry transport model, Max-Planck-Institut für Meteorologie Report, 227, 1997, submitted to Atmospheric Environment.

Langner, J., H. Rodhe, P. Crutzen, and P.H. Zimmermann, Anthropogenic influence on the distribution of tropospheric sulphate aerosol, Nature, 359, 712-715, 1992.

Liss, P. S., and L. Merlivat, Air-sea gas exchange rates: Introduction and synthesis, in The Role of Air-Sea Exchange in Geochemical Cycling, edited by P. Buat-Menard, pp. 113-127, D. Reidel, Norwell, Mass., 1986.

Matsuno, S., On the origin of volcanic gases, J. Earth Sci. Nagoya Univ., 8, 222-245, 1960.

McClelland, L., T. Simkin, M. Summers, E. Nielsen, and T. C. Stein, Global Volcanism 1975-1985, 655 pp, Prentice-Hall, Englewood Cliffs, N. J., 1989.

Mitchell, J. F. B., T. C. Johns, J. M. Gregory, and S. F. B. Tett, Climate response to increasing levels of greenhouse gases and sulfate aerosols, Nature, 376, 501-504, 1995.

Nemesure, S., R. Wagner, and S. E. Schwartz, Direct shortwave forcing of climate by the anthropogenic sulfate aerosol: Sensitivity to particle size, composition, and relative humidity, J. Geophys. Res., 100, 26,105-26,116, 1995.

Newhall, C. G, and S. Self, The volcanic explosivity index (VEI): An estimate of explosive magnitude for historical volcanism, J. Geophys. Res., 87, 1231-1238, 1982.

Nordeng, T. E., Extended versions of the convective parameterization scheme at ECMWF and their impact on the mean and transient activity of the model in the tropics, J. R. Meteorol. Soc., in press, 1996.

Pham, M., J.-F. Muller, G. P. Brasseur, C. Granier, and G. Megie, A threedimensional study of the tropospheric sulfur cycle, J. Geophys. Res., 100, 26,061-26,092, 1995.

Platnick, S., and S. Twomey, Determining the susceptibility of cloud albedo to changes in droplet concentration with the advanced very high resolution radiometer, J. Appl. Meteorol., 33, 334-347, 1994.

Rasch, P., and D. Williamson, Computational aspects of moisture transport in global models of the atmosphere, Q.J.R. Meteorol. Soc., 116, 1071$1090,1990$.

Roeckner, E., Parameterization of cloud radiative properties in the ECHAM4 model, in Proceedings of the Workshop on Cloud Micro. physics Parameterizations in Global Atmospheric Circulation Models, 
edited by D. Randall, WMO/TD-713, World Meteorol. Org., Geneva, 1995.

Roeckner, et al., Simulation of the present-day climate with the ECHAM model: Impact of model physics and resolution, Rep. 93, Max-PlanckInst. for Meteorol., Hamburg, Germany, 1992.

Roeckner, E., T. Siebert, and J. Feichter Climate response to anthropogenic sulfate forcing simulated with a general circulation model, in Proceedings of the Dahlem Workshop on Aerosol Forcing of Climate, edited by R. J. Charlson and J. Heintzenberg, pp. 349-362, John Wley, New York, 1995.

Rose, W. I., G. Heiken, K. Wohletz, D. Eppler, S. Bar, T. Miller, R. L. Chuan, and R.B Symonds, Direct rate measurements of eruption plumes at Augustine Volcano: A problem of scaling and uncontrolled variables, J. Geophys. Res., 93, 4485-4499, 1988.

Saltbones, J., and H. Dovland, Emissions of sulfur dioxide in Europe in 1980 and 1983, EMEP/CCC-Report, 1/86, NILU, Lillestøm, Norway, 1986.

Spiro, P. A., D. J. Jacob, and J. A. Logan, Global inventory of sulfur emissions with $1^{\circ} \times 1^{\circ}$ resolution, J. Geophys. Res., 97, 6023-6036, 1992.

Stoiber, R. E., and A. Jepsen, Sulfur dioxide contribution to the atmosphere by volcanoes, Science, 182, 577-578, 1973.

Stoiber, R. E., L. L. Malinconico, and S. N. Williams, Use of the correla- tion spectrometer at volcanoes, in Forecasting Volcanic Events, edited by H. Tazieff and J. C. Satroux, pp. 425-444, Elsevier, New York, 1983. Stoiber, R.E., S. N. Williams, and B. Huebert, Annual contribution of sulfur dioxide to the atmosphere by volcanoes, J. Volcanol. Geotherm. Res., 33, 1-8, 1987.

Sundquist, H., A parameterization scheme for non-convective condensation including prediction of cloud water content, J. R. Meteorol. Soc, 104, 677-690, 1978.

Taylor, K., and J. E. Penner, Response of the climate system to atmospheric aerosols and greenhouse gases, Nature, 369, 734-737, 1994.

Thordarson, T. and S. Self, The Laki (Skaftár Fires) and Grimsvötn eruptions in 1783-1785, Bull. Volcanol., 55, 233-263, 1993.

Tiedtke, M., A comprehensive mass flux scheme for cumulus parameterization in large-scale models, Mon. Weather Rev., 117, 1779-1800, 1989.

J. Feichter, H.-F. Graf, and B. Langmann, Max-Planck-Institut für Meteorologie, Bundesstrasse 55, D-20146 Hamburg, Germany. (e-mail: feichten@dkrz.de; graf@dkrz.de; langmann@dkrz.de)

(Received June 1, 1996; revised September 17, 1996; accepted September 17, 1996.) 